cludes syndetic devices was a guiding principle in the development of AACR1. According to Lubetzky, this view has been lost in the new code, which reflects a view of the catalog as a finding list.

The importance of Lubetzky's comments is underscored by $\mathrm{S}$. Michael Malinconico in "AACR2 and Automation." Malinconico points out that although automation can make it easier for libraries to accommodate changes in bibliographical principles, such principles exist independently from any technology and must be developed in isolation from computers, despite the intention of drafters of the new code "to take developments in library automation into account." Malinconico notes that the concept of the main entry, despite its demise in AACR2, reappears in the frequently forwarded suggestion that automated systems can compensate for the absence of the main entry and collocation function by linking various versions of a work. However, the ability of most systems to accomplish this or to support any of the extensive modifications necessary to implement the new code well is not evident at this time. He argues that the time to implement a new cataloging code would have been at a point when this kind of support was available.

Malinconico also lists some accommodations to automation that are evident in the new code, although his opinion of at least two of these is that the code has found solutions to relatively trivial problems. For example, the filing provisions in AACR2 occasionally result in forms of access that-while easily processed by machine-look peculiar to the people reading them. He points out that in the experience of the New York Public Library, reliance on manual filing forms when necessary has caused no major problems. In addition, use of rigid punctuation rules to help machine sorting will not be as effective as the consistent use of explicit content designators that already exist in the MARC format.

The Making of a Code will be an important text on the development of the second edition of AACR for future students of cataloging history. For the present, it raises questions and doubts about the code that continue to be troublesome and controversial.
In The Handbook for AACR2, Margaret Maxwell presents a useful explication of the new code by providing clear explanations of specific rules, numerous full catalog entry format examples illustrating code prescriptions, transcriptions of title pages from which the examples are derived, and references to treatment of specific topics in earlier codes when possible and appropriate. The Handbook also includes helpful appendixes such as descriptions of anonymous classics; AACR2 forms of headings for U.S. presidents, British sovereigns, etc.; and indexes to rules, examples, and topics covered in the book. Library of Congress practice is reflected as much as possible in the text and examples.

Most valuable to nonspecialist catalogers will be the chapters on special materials that provide examples of cataloging of motion pictures, video records, graphic materials, three-dimensional artifacts and realiaitems that many catalogers encounter only occasionally and that present problems because of their rarity in many collections.

Although the Handbook will not take the place of the example files most catalogers compile to illustrate unusual problems they solve in their work, it does provide a very useful basic collection that, together with the explanations, will be valuable for training purposes in both libraries and library schools, and for general consultation in catalog departments.-Tina Kass, Research Libraries Group, Stanford, California.

Roper, Fred W., and Boorkman, Jo Anne.

Introduction to Reference Sources in the

Health Sciences. Chicago: Medical Library Association, 1980. 252p. \$18. ISBN 0-912176-08-3.

Roper and Boorkman are the principal authors of this work, writing nine of the fourteen chapters; the remaining chapters were contributed by librarians from various health sciences libraries around the country. Intended primarily for use as a library school text, this book should be equally useful to practicing librarians and library users.

The first chapter covers the organization and management of a reference collection. It offers no cut-and-dried blueprint, but rather a discussion of alternatives and the factors to be considered when making deci- 
sions about particular situations. The remaining thirteen chapters are the real meat of the book, however, and deal primarily with specialized sources of information in the health sciences.

Unlike the heavily subject-oriented approach followed by authors like Lunin and Morton, this volume is divided into two general sections-bibliographic sources and information sources. Each chapter within a section deals with a particular type of bibliographic or information resource, providing both a discussion of the general characteristics of the type and examples of the most important sources, with a brief description of the major features of each. The titles cited do not provide an exhaustive listing, but rather are the authors' choice of core titles for each type. Suggested additional readings are also included for each chapter.

The section on bibliographic sources begins with two chapters discussing general sources of bibliographic information on monographs and periodical titles, followed by discussions of the major abstracting and indexing services and the computerized databases that are currently available. The final two chapters of this section cover sources of information for government documents, technical reports, conferences, reviews, and translations.

The section on information sources contains chapters on terminology, handbooks and manuals, drug information, audiovisuals, medical and health statistics, directories and biographical sources, and history sources. The chapters dealing with conferences, audiovisuals, and statistics may be particularly useful, as these topics are not often addressed in this manner.

This book will not be of particular value to the person seeking a specific source in a particular subject area. It will, however, be a tremendous help to the individual who is trying to determine how and where to find such information as statistical data, biographical data, or information about audiovisuals in the health sciences. These individuals are probably in training to become reference librarians in a health sciences library, but they could just as easily be library patrons or reference librarians in any general academic or research library.-Eliz-

\section{DID YOU KNOW THAT}

\section{The Official Washington Post Index IS THE ONLY INDEX TO THE WASHINGTON POST THAT}

- is officially sanctioned by the Post Publishing Company

- covers all levels of news from international to local

- includes editorials, letters, syndicated columns, and reviews

- uses free language abstracts which provide so much information users may not need to use the newspaper at all

- has locators which refer the user to the page and column to which an Index item actually refers, not just to the beginning of a story.

Do you want to know more about

The Official Washington

Post Index?

Call or write:

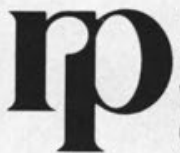

Research Publications, Inc.

12 Lunar Drive

Woodbridge, CT 06525

(203) $397-2600$ 
abeth Sawyers, Health Sciences Library, Ohio State University, Columbus.

\section{SantaVicca, Edmund F. Reference Work in}

the Humanities. Metuchen, N.J.: Scarecrow, 1980. 173p. \$9. LC 80-18783. ISBN 0-8108-1342-4.

The title of this book may lead the reader to expect a treatise on reference work in the humanities. This work actually presents a variety of reference questions and case studies organized by subject. The subjects covered are philosophy, religion and mythology, literature, music, fine arts, and theater arts; there is also a chapter on interdisciplinary problems. Each subject area has a set of exercises, divided into three sections: questions, search problems, and case studies. The exercises are designed to familiarize readers with the disciplines that make up the humanities; to introduce the reader to the difficulties and complexities of the reference interview; and to provide search problems for every subject area using appropriate examples. Unfortunately, the author does not provide solutions to search problems. The appendix gives some examples of possible solutions in a few subject areas, but it seems that a book of this type should have solutions, or at least some suggestions on finding answers to the questions posed. This is also true for the case studies; no examples of possible solutions are given. Even if the main function of this work is to serve as a workbook in a classroom situation, suggested solutions appended at the end of the book would have enhanced its usefulness.

The approach employed in this book helps the reader to understand how to translate the language of the library user into the terminology of potential retrieval systems in a given library situation. Often too much emphasis has been placed by the library science curriculum and by practicing reference librarians on the nature and reference qualities of specific reference titles, and too little emphasis on understanding how these qualities come into play in the process of reference work. In this respect the author is successful in identifying a number of questions that help to distinguish the difference between these two processes.

In the absence of other titles in the area of reference service in the humanities, this work is a good beginning. The questions selected in the exercises are phrased in a variety of ways, having varying degrees of clarity and ambiguity and differing levels of depth, which may help the reader to understand the kinds of questions he/she will encounter. A major weakness is the lack of a bibliography or notes suggesting further reading. This is a serious flaw in the book. One cannot help but compare this work with Reference Books in the Social Sciences and Humanities by R. E. Stevens (Stipes, 1977). The latter work is broader in scope and provides extensive information on several hundred specific reference books in the social sciences and humanities. (Stevens' title referred to here is out of print. Available is Reference Books in the Social Sciences by R. Stevens and D. Davis [Stipes, 1977].) Had these features been present in SantaVicca's book, they would have considerably increased its value.-George $\mathrm{V}$. Hodowanec, Emporia State University, Emporia, Kansas.

ERIC Clearinghouse on Information Resources. ERIC Basics; a Sound/Microfiche Instructional Package. Syracuse, N.Y., 1979. 53-frame color microfiche, 12minute audiocassette. \$10. (Available from: Information Resources Pubs., 130 Huntington Hall, Syracuse University, Syracuse, NY 13210.)

This unusual pairing of media formats, a cassette and microfiche, is attractively boxed and easy to use. Its aim is to teach the uninitiated how to use the two ERIC indexes, Resources in Education (RIE) and Current Index to Journals in Education $(C I J E)$, in order to access the ERIC document collection and periodical literature in the field of education. It succeeds admirably. The narrators assume nothing yet are not insulting. A woman gives clear instructions on how to load and follow the fiche, and these instructions are repeated at appropriate points. A man presents the content, and again is concise and clear. Visually, the fiche frames are simple yet effective; the use of color and the repetition of cover shots of the three sources discussed (RIE, CIJE, and the Thesaurus of ERIC Descriptors) reinforce the information that 